\title{
Acute effects of pre-workout supplement on aerobic and anaerobic performance in basketball players
}

\author{
Çetin O. ${ }^{1 \mathrm{ABCDE}}$, Yaşar M.N. ${ }^{1 \mathrm{ABCDE}}$, Demirtaş B. ${ }^{1 \mathrm{ABCDE}}$, Beyleroğlu M. ${ }^{1 \mathrm{ABCDE}}$, Eker S. ${ }^{2 \mathrm{ABCDE}}$, Gürkan A.C. ${ }^{3 \mathrm{ABCDE}}$ \\ ${ }^{1}$ Sakarya University of Applied Sciences, Faculty of Sport Sciences, Sakarya, Turkey \\ ${ }^{2}$ Ministry of Health Sakarya University Education and Research Hospital, Sakarya, Turkey \\ ${ }^{3}$ Iğdır University, Physical Education and Sports High School, I ğdır, Turkey
}

Authors' Contribution: A - Study design; B - Data collection; C - Statistical analysis; D - Manuscript Preparation; E - Funds Collection.

\begin{abstract}
Purpose: In recent years, the use of ergogenic aid has become widespread in order to improve performance among the athletes and to achieve success more easily. Pre-workout nutritional supplements that attract the attention of many athletes as a legal ergogenic aid are used by both aerobic and anaerobic branch athletes. The aim of this study is to examine the acute effect of the pre-workout supplement on aerobic and anaerobic performance in basketball players.

Material: $\quad$ Twenty male college basketball players who have played regularly at least for 5 years participated in the study voluntarily (mean \pm SD $22.00 \pm 1.70$ years, height $1.83 \pm 0.07 \mathrm{~cm}$, weight $85.15 \pm 10.78 \mathrm{~kg}, \mathrm{BMI} 25.32 \pm$ 3.10). Double-blind placebo-controlled, cross-over method was used for the collection of data. The players were divided into two groups as placebo $(P L, n=10)$ and pre-workout ( $P R W, n=10)$. Placebo and pre-workout groups were replaced 48 hours after the initial measurements and the same tests were repeated. The preworkout group was given $17 \mathrm{gr}$ (Bigjoy Predator) in $200 \mathrm{mg}$ of additive-free juice 1 hour before the test, only $200 \mathrm{mg}$ of additive free juice was given to the placebo group. Countermovement Jump (CMJ) and RunningBased Anaerobic Sprint Test (RAST) were used to measure the anaerobic performance of the athletes, and Yoyo Intermittent Recovery Test 1(Yo-Yo IRL1) was used to measure aerobic capacities.
\end{abstract}

Results: $\quad$ A significant difference was found concerning the Countermovement Jump (CMJ) test results $(p=0,004)$, Relative peak power $(p=0.001)$ and Relative average power $(p=0.012)$ values obtained from RAST test data. There was no significant difference in fatigue index $(p=0.79)$ and $\mathrm{VO}_{2}$ max $(p=0.492)$ values.

Conclusions: While pre-workout supplementation has an acute effect on anaerobic power data, it has been observed that there is no acute effect on the data obtained from fatigue index and aerobic endurance test.

Keywords: basketball, aerobic performance, anaerobic performance, pre-workout, acute effect.

\section{Introduction}

As for the recent years, use of ergogenic aid has gained wide currency among the athletes with the aim of increasing the performance and attaining success in an easier manner [1-3]. Ergogenic aids, which contribute to the increase of training and match performance and are not considered as doping, are nutritional supplements [4]. In this sense, one of these ergogenic aids is pre-workouts which increase the performance, training adaptation, energy-production/use of athletes as well as support the recovery $[2,5]$.

Pre-workout nutritional supplements which attract the attention of many athletes by virtue of its being a legal ergogenic aid are used by aerobic and anaerobic branch athletes due to their potential ergogenic effects [6]. Producers of multi-ingredient pre-workouts generally claim that their products enhance the performance of athletes and reduce the fatigue sensation during the exercise. These products characteristically include a combination of many ingredients $(30+)$ and generally contain stimulants (e.g. caffeine), energy-producing factors (e.g. creatinee), agents which act as hydrogen ion buffers (e.g. beta alanine), protein recovery nutrients (e.g. amino acids), antioxidants as well as nitric oxide

\footnotetext{
(c) Çetin O., Yaşar M.N., Demirtaş B., Beyleroğlu M.,

Eker S., Gürkan A.C., 2019

doi:10.15561/20755279.2019.0103
}

precursors (e.g. arginine) [7].

When the literature concerning this aspect is examined, it is observed that there are studies with respect to the effect of pre-workout nutritional supplement on athlete's aerobic and anaerobic performances [5, $8-11]$. To illustrate, Martinez et al. [9] investigated the acute effects of caffeine-containing pre-workout nutritional supplement on anaerobic power for men who work out recreationally, and reported that these supplements lead to significant improvements in the values of anaerobic peak power and mean power. In a similar study, Jagim et al. [10] examined the effects of multi-ingredient pre-workout ingestion on strength performance, lower body power and anaerobic capacity in resistance trained collegeaged men, and concluded that this supplement improved the mean power in anaerobic running capacity test. Furthermore, Smith et al. [8] examined the effect of using pre-workout, which contains caffeine, creatine and amino acid, together with high-intensity exercises on the aerobic and anaerobic performance in moderately-trained men and reported that there were improvements with regard to $\mathrm{VO} 2_{\text {max }}$ values of the participants. Cameron et al. [5] found that as a result of their studies which examine the acute effect of multi-ingredient pre-workout supplement on resting energy expenditure and exercise performance of recreationally active women, pre-workout supplement improves diastolic blood pressure, resting metabolism, 
upper body muscular strength and anaerobic capacity.

Furthermore, the integration of nutritional supplements into researches by means of realistic exercise training protocols will allow for sportive practical uses. Particularly, intermittent running trainings, which are practicable for team sports based on repeated bouts of short sprints such as football, basketball, hockey and soccer as well as practicable for team sports based on active recovery periods, are sensitive to additional nutritional supplements which are designed to delay fatigue resulting from considerably extensive training [8].

Although there are studies examining the acute $[5,10$, 12] and chronic $[8,9]$ effects of the use of pre-workout nutritional supplements, it is observed that these studies are mostly performed on individuals who perform sports individually and in a recreative manner. Furthermore, it is observed that there is a limited number of studies which examines the effect of these supplements on performance in team sports which include intermittent running and is bound up with aerobic and anaerobic systems. Accordingly, the purpose of this study is to investigate the acute effect of pre-workout nutritional supplementation on aerobic and anaerobic performance in basketball players.

\section{Material and methods}

\section{Participants}

20 athletes from Sakarya University Basketball Team, who have at least 5 years of athletic background and have not taken any nutritional supplement in the last 6 months, participated in this study (mean $\pm \mathrm{SD} 22,00 \pm 1,70 \mathrm{yrs}$; height 1, $83 \pm 0,07 \mathrm{~cm}$; weight $85,15 \pm 10,78 \mathrm{~kg}$; BMI 25 , $32 \pm 3,10)$.

Furthermore, they were informed about the objective and significance of the study as wells as the benefits and risk of the nutritional supplement to be consumed; moreover, their voluntary participation was ensured. For this study, ethical approval (numbered 16214662/050.01.04/70) was received from Sakarya University Department of Medical Research Ethical Committee.

Research Design

In this study, double-blind placebo-controlled crossover method was used. Aerobic and anaerobic tests were performed on the participants on 4 separate measurement dates which had 48 hours interval among each other. As for the $1^{\text {st }}$ measurement day, CMJ and RAST tests were performed on the placebo and pre-workout groups. As to $2^{\text {nd }}$ measurement day, the same tests were repeated by replacing placebo and pre-workout groups. Concerning $3^{\text {rd }}$ day, Yo-Yo IRL1 test was performed. With regard to $4^{\text {th }}$ day, Yo-Yo IRL1 test was repeated by replacing placebo and pre-workout groups (Figure 1). A dietary control was performed on the athletes 3 hours prior before the measurements, and they were demanded not to consume caffeine during this study. Additionally, pre-workout and placebo products were given to athletes by independent nutrition expert one hour before the tests. The athletes were demanded to maintain their current training program during the study. Besides, the athletes were also instructed to refrain from doing any compelling physical activity other than their own training. Before the tests, the athletes were informed about the test protocols and a demonstration regarding these tests was performed. Moreover, athletes completed a 10-minute standard warm-up procedure consisting of low intensity running, dynamic stretching of the lower body and vertical jump exercises before each test.

\section{Measurements and Tests}

Body weights of the athletes were measured by "Tanita Segmental Body Composition Monitor InnerScan BC$545 \mathrm{~N}$ - Japan"; on the other hand, height measurements (Seca 213 Germany) were measured with $1 \mathrm{~mm}$ precision portable stadiometer. Furthermore, their body-mass indexes were calculated with the formula Bodyweight / height2 (m). In CMJ test, leg lengths of the athletes were measured and standardized in accordance with $\mathrm{CMJ}$ test. Besides, CMJ and RAST were used to measure anaerobic performance of the athletes; additionally, YoYo IRL1 test was used to measure aerobic performance. The mentioned measurements were performed within 4 days at 48-hour intervals and they were realized during the same training hours at Sakarya University Faculty of Sports Sciences Indoor Sports Facility. The same dietary control was performed on the athletes 3 hours before the measurements.

\section{Running-Based Anaerobic Sprint (RAST) Test}

The Running-Based Anaerobic Sprint Test (RAST), which was developed by Draper and Whyte at the University of Wolverhampton in the United Kingdom in 1997 , is a test protocol designed to measure anaerobic power and capacity [13]. The test includes 6 sprints over a distance of 35 meters with an active resting time of 10 seconds for each sprint. In this sense, after the participants were informed about the test, a specific 10-minutes warmup protocol was performed. Moreover, photocell (SE-100 Chronometer) was used during the tests. Within the scope of the RAST test; relative peak power, relative average power as well as fatigue index data were collected in an indirect way.

\section{Countermovement Jump Test}

Jump performance (explosive power) has a significant role in the branches in which aerobic or/and anaerobic energy systems are used [14]. In this study, My Jump 2 application (app), which was accessed via the iPhone Apple Store, was used to measure the vertical jump performance $(\mathrm{ICC}=0.97-0.99)$ [14]. The My Jump 2 app has been developed to calculate the jump height from flight time using the high-speed video recording feature via iPhone 6S [15]. Each participant was allowed to jump for three times and their best scores were recorded.

\section{Yoyo Intermittent Recovery Test 1}

The Yo-Yo IRL1 test consists of $2 * 20$-meter shuttle runs that are repeated with incremental speed increases controlled by commands from a laptop audio file between the start, rotation and termination lines. Each interval between the shuttle runs includes an active recovery time of 10 seconds in which the athletes walk or jog in a $2 *$ 5 -meter area. If the athletes fail to reach the finish line for two times, the test is terminated and the total distance 


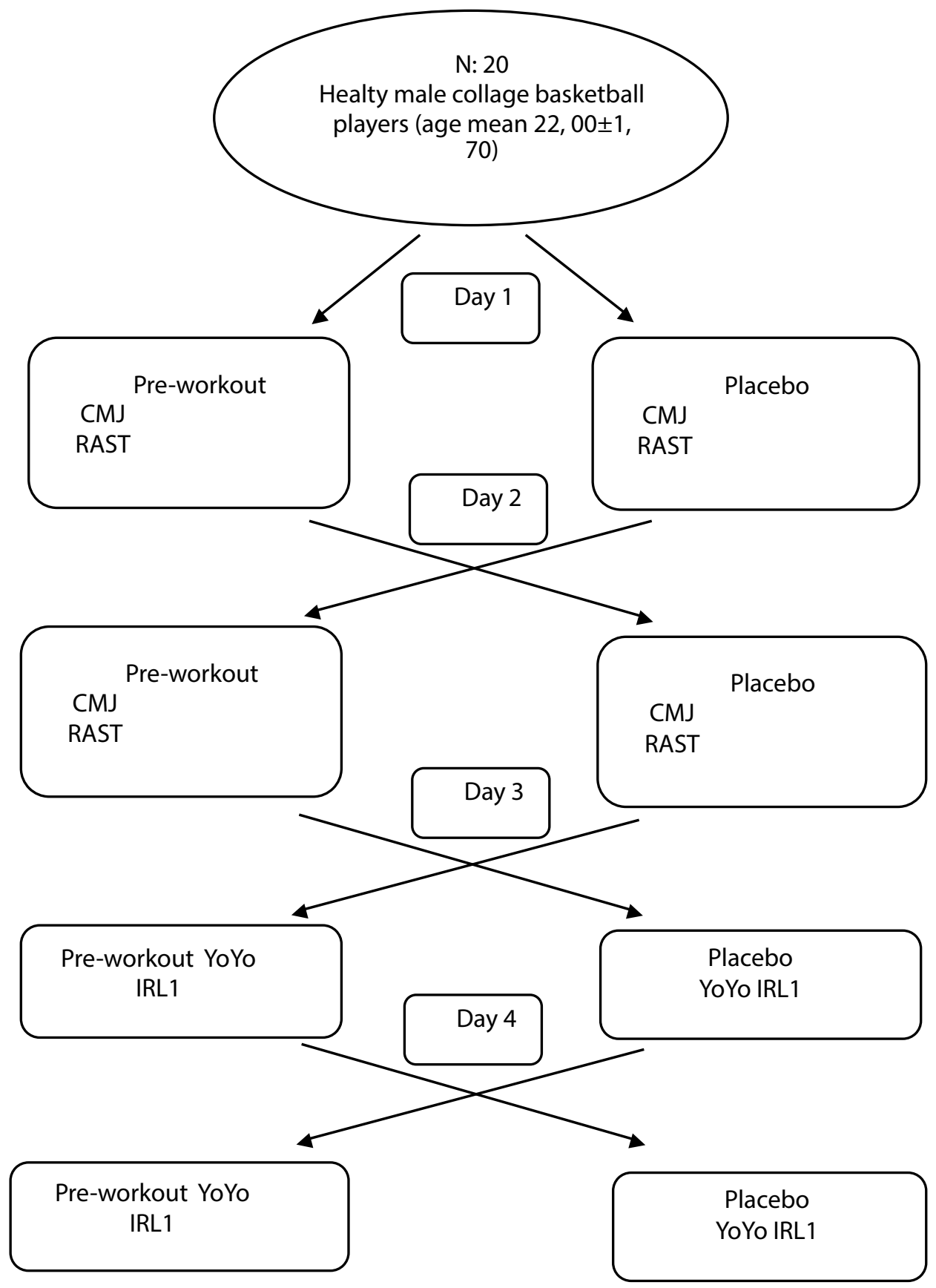

Figure 1. Schematic representation of the experimental sessions.

covered by the athlete is recorded as a test result. In this framework, the total duration of the test was 6-20 minutes $[16,17]$. VO2max was measured indirectly from the YoYo test.

\section{Supplement Consumption}

In this study, double-blind placebo-controlled crossover was used. Moreover, the pre-workout group was given 17 gram of BigJoy Predator (Forest Fruity, 510 gr) by mixing it with $250 \mathrm{ml}$ of organic fruit juice which has the same aroma with pre-workout product. As for the placebo group, they only received $250 \mathrm{ml}$ of unmixed fruit juice with the same aroma as the pre-workout. The contents of the pre-workout product used in the study are shown in Figure 2.

Dietary control
Participants were selected from healthy athletes who had not received any ergogenic dietary supplement for 6 months before the measurements. Participants were demanded not to take alcohol, caffeine, or any other drugs within 48 hours prior to the measurements. Moreover, participants were asked not to change their dietary habits during the study period. However, the foods to be consumed on the measurement days were determined. Furthermore, all participants consumed the same food 3 hours before each measurement. Meal contents were prepared in accordance with the principle of a balanced diet, which includes various energy sources and macronutrients [18]. The contents of each meal - totally four meals- which were consumed before measurement were similar. 


\begin{tabular}{|ll|}
\hline Bigjoy Predator & \\
Energy & $4 \mathrm{kcal}$ \\
Fat & $0,0 \mathrm{~g}$ \\
Protein & $0,0 \mathrm{~g}$ \\
Vitamin Content & \\
Vitamin B3 & $20 \mathrm{mg}$ \\
Vitamin B6 & $2.4 \mathrm{mg}$ \\
Vitamin B12 & $200 \mathrm{mcg}$ \\
BCAA & $3000 \mathrm{mg}$ \\
Leucine & $2000 \mathrm{mg}$ \\
Isoleucine & $500 \mathrm{mg}$ \\
Valine & $500 \mathrm{mg}$ \\
Arginine(AKG) & $3000 \mathrm{mg}$ \\
Beta Alanine & $2800 \mathrm{mg}$ \\
Creatinee Monohydrate & $1500 \mathrm{mg}$ \\
Citruline & $1000 \mathrm{mg}$ \\
Taurine & $800 \mathrm{mg}$ \\
Caffeine & $210 \mathrm{mg}$ \\
Tyrosine & $200 \mathrm{mg}$ \\
Guarana Extract (Paulina Cupana) & $50 \mathrm{mg}$ \\
Citrus Extract (Citrus Aurantium) & $50 \mathrm{mg}$ \\
Ginseng (Panax) & $20 \mathrm{mg}$ \\
Electrolyte Mixture & $395.5 \mathrm{mg}$ \\
Sodium & $318 \mathrm{mg}$ \\
Potassium & $59.3 \mathrm{mg}$ \\
Magnesium & $9.20 \mathrm{mg}$ \\
\hline
\end{tabular}

Figure 2. Ingredients of pre-workout

Table 1. Descriptive Statistics of participants

\begin{tabular}{llllll}
\hline Indicators & $\mathbf{N}$ & Minimum & Maximum & Mean & Std. Dev. \\
\hline Age & 20 & 19.00 & 25.00 & 22.00 & 1.70 \\
Height & 20 & 1.67 & 1.93 & 1.83 & 0.07 \\
Body Weight & 20 & 62.30 & 104.20 & 85.15 & 10.78 \\
Body Mass Index & 20 & 18.60 & 31.02 & 25.32 & 3.10 \\
Leg Height & 20 & 93.00 & 117.00 & 104.75 & 5.48 \\
\hline
\end{tabular}

\section{Statistical Analysis}

Descriptive statistics (mean and standard deviation) of all data were calculated. Besides, normality test of the obtained data was analyzed by the Shapiro-Wilk test. Wilcoxon Signed Rank test was used to analyze the data that were not distributed normally. Significance was determined as $p<0.05$. SPSS software was used in analyzing the data.

\section{Results}

The age average of basketball players participating in the research was determined as $22.00 \pm 1.70$; additionally, the mean height was $1.83 \pm 0.07$, the mean body weight was $85.15 \pm 10.78$, the body mass index average was 
Table 2. Comparison of athletic performance variables of participants

\begin{tabular}{|c|c|c|c|c|c|}
\hline Variables & Groups & $\mathbf{N}$ & Mean \pm Std. Dev. & $\mathbf{Z}$ & $\mathbf{P}$ \\
\hline $\begin{array}{l}\text { Countermovement jump } \\
(\mathrm{cm})\end{array}$ & $\begin{array}{l}\text { Placebo } \\
\text { Pre-Workout }\end{array}$ & 20 & $\begin{array}{l}44.13 \pm 5.39 \\
45.12 \pm 5.23\end{array}$ & -2.913 & $0.004 * *$ \\
\hline $\begin{array}{l}\text { Relative peak power } \\
\left(\mathrm{w} . \mathrm{kg}^{-1}\right)\end{array}$ & $\begin{array}{l}\text { Placebo } \\
\text { Pre-Workout }\end{array}$ & 20 & $\begin{array}{l}9.02 \pm 1.90 \\
10.02 \pm 1.72\end{array}$ & -3.323 & $0.001 * *$ \\
\hline $\begin{array}{l}\text { Relative average power } \\
\left(\mathrm{w}_{\mathrm{kg}}^{-1}\right)\end{array}$ & $\begin{array}{l}\text { Placebo } \\
\text { Pre-Workout }\end{array}$ & 20 & $\begin{array}{l}7.40 \pm 1.26 \\
7.88 \pm 1.30\end{array}$ & -2.501 & $0.012 * *$ \\
\hline $\begin{array}{l}\text { Fatigue index } \\
\text { (watts/sec) }\end{array}$ & Pre-Workout & 20 & $\begin{array}{l}8.03 \pm 3.60 \\
9.50 \pm 3.22\end{array}$ & -1.755 & 0.79 \\
\hline $\begin{array}{l}\mathrm{VO}_{\text {max }} \\
(\mathrm{ml} / \mathrm{kg} / \mathrm{dk})\end{array}$ & Pre-Workout & 20 & 42.161 .75 & -0.687 & 0.492 \\
\hline
\end{tabular}

$25.32 \pm 3.10$ and ultimately the mean of the leg length was $104,75 \pm 5.48$.

In examining the difference among the athletic performance variables of basketball players, while there was a difference among the values of CMJ, Relative Peak Power and Relative Average Power, it was observed that there was no difference between the values of fatigue and VO2max $(\mathrm{p}<0.05)$.

\section{Discussion}

The aim of this study is to examine the effect of preworkout use on aerobic and anaerobic performance for basketball players. According to the results of this study, it was observed that pre-workout supplement consumption had a positive effect on the test results which measured anaerobic performance of the basketball players but had no positive effect on aerobic performance. When relevant studies in this subject are examined, it is observed that these studies support the anaerobic performance results of this study. For instance; Cameron et al. [5] used CMJ testing to measure anaerobic performance in their study with respect to the acute effect of a multi-ingredient preworkout supplement on exercise in recreationally active females. As a result, they reported that the multi-ingredient pre-workout supplement had a positive effect on anaerobic performance. As for another similar study, Kreamer et al. [19] investigated the effect of multi-ingredient nutritional supplementation on exercise performance and hormonal responses concerning 9 healthy males; and reported that multi-ingredient nutritional supplementation improved vertical jump test results which is an indicator of anaerobic performance. In contrast to these studies, Dawes et al. [20] found no significant difference with regard to anaerobic power in their studies which examine the effect of preworkout energy drink on physical performance of 41 healthy males. However, it was determined that there was difference between the values of relative average power and relative peak power which were obtained by means of RAST Test. Besides, the reason why anaerobic power results found by Dawes and his colleagues diverge from the results of this study and other cited studies is thought to be resulted from the sample group that has less training background. Furthermore, Gonzales et al. [6] studied the effects of pre-workout supplement on multi-joint endurance exercise regarding eight athletes with a mean 5-year endurance training history. Consequently, they concluded that pre-workout supplementation significantly increased mean and peak power values. Similarly, within the scope of their studies which examines the effect of multi-ingredient pre-workout on strength performance, lower body strength and anaerobic capacity of collegeaged individuals with endurance training background, Jagim et al. [10] found that mean power values which are calculated indirectly from the maximum force test of athletes using pre-workout were high.

It is observed that different results have been obtained in the studies which examine the chronic effects of the use of pre-workout derivative supplement on aerobic $\left(\mathrm{VO} 2_{\max }\right)$ 
and anaerobic performances of athletes. For example, Urbina et al. [21] found no significant difference with respect to the effect of 6 -week pre-workout nutritional supplementation and post-training protein ingestion on the $\mathrm{VO} 2_{\text {max }}$ values of individuals who do crossfit. On the other hand, Smith et al. [8] examined the effect of the use of high-intensity interval training together with pre-workout containing caffeine, creatine and amino acid for 3 weeks on aerobic and anaerobic performance of moderatelytrained males and concluded that there was improvement with regard to $\mathrm{VO} 2_{\text {max }}$ in their research. Additionally, In consequence of their studies which examine the effect of the combination of pre-workout nutritional supplements and 3-week high-intensity interval training on critical speed, anaerobic running capacity, training volume and body composition with regard to men and women (25 well-trained recreational athletes), Smith et al. [22] showed that $\mathrm{VO} 2_{\max }$ increased with the rate of $\% 10.5$. It

\section{References}

1. Ünal M. The Effects of Creatinee Supplementation on Athletes and Exercise Performance. Genel Tip Derg. 2005;15(1):43-50.

2. Kreider RB, Wilborn CD, Taylor L, Campbell B, Almada AL, Collins R, etal.ISSN exercise \& sportnutrition review: research \& recommendations. J Int Soc Sport Nutr. 2010;7(7): 1-43. https://doi.org/10.1186/1550-2783-7-7

3. Kerksick C, Harvey T, Stout J, Campbell B, Wilborn C, Kreider R, et al. International society of sports nutrition position stand: Nutrient timing. J Int Soc Sports Nutr. 2008;5(17):1-12.

4. Kürkçü, Recep; Can, Süleyman; Durukan E. Farklı Branşlardaki Üniversiteli Sporcuların Ergojenik Yardımcılar Konusundaki Bilgi ve Yararlanma Düzeylerinin Araștırılması [The investigation of the knowledge and the application levels universty athletes in different branches about ergogenic AİDS]. New World Sci Acad. 2009;4(3):198-209.

5. Cameron M, Camic CL, Doberstein S, Erickson JL, Jagim AR. The acute effects of a multi-ingredient pre-workoutsupplement on resting energy expenditure and exercise performance in recreationally active females. JInt Soc Sports Nutr. 2018;15: 1 . https://doi.org/10.1186/s12970-017-0206-7

6. Gonzalez AM, Walsh AL, Ratamess NA, Kang J, Hoffman JR. Effect of a pre-workout energy supplement on acute multijoint resistance exercise. J Sport Sci Med. 2011;10(2):261-6.

7. Bloomer RJ, Farney TM, Trepanowski JF, McCarthy CG, Canale RE, Schilling BK. Comparison of pre-workout nitric oxide stimulating dietary supplements on skeletal muscle oxygen saturation, blood nitrate/nitrite, lipid peroxidation, and upper body exercise performance in resistance trained men. J Int Soc Sports Nutr. 2010;7(16): 1-15. https://doi.org/10.1186/1550-2783-7-16

8. Smith AE, Fukuda DH, Kendall KL, Stout JR. The effects of a pre-workout supplement containing caffeine, creatinee, and amino acids during three weeks of high-intensity exercise on aerobic and anaerobic performance. J Int Soc Sports Nutr. 2010;7(10):1-11.

9. MartinezN,CampbellB,FranekM,Buchanan L, ColquhounR. The effect of acute pre-workout supplementation on power and strength performance. J Int Soc Sports Nutr. 2016;13(1): 1-7. https://doi.org/10.1186/s12970-016-0138-7

10.Jagim AR, Jones MT, Wright GA, St. Antoine C, Kovacs A, is evaluated that the scope and intensity of the applied training programs can be influential with respect to the fact that study results dealing with the chronic effects of pre-workout differ.

\section{Conclusion}

The acute effects of pre-workout supplement on anaerobic and aerobic performance of basketball players were examined in this study. It was determined that CMJ test and RAST test values which are anaerobic capacity indicators of the athletes using pre-workout supplement were higher. However, there were no differences between the fatigue index obtained from RAST test and $\mathrm{VO}_{\text {max }}$ values which were indirectly obtained from the aerobic capacity test.

\section{Conflict of interest}

The authors declare no conflict of interest.
Oliver JM. The acute effects of multi-ingredient pre-workout ingestion on strength performance, lower body power, and anaerobic capacity. J Int Soc Sports Nutr, 2016;13(1): 1-10. https://doi.org/10.1186/s12970-016-0122-2

11. Spradley BD, Crowley KR, Tai CY, Kendall KL, Fukuda DH, Esposito EN, et al. Ingesting a preworkout supplement containing caffeine, B-vitamins, amino acids, creatinee, and beta-alanine before exercise delays fatigue while improving reaction time and muscular endurance. Nutr Metab, 2012;9(1): 28. https://doi.org/10.1186/1743-7075-9-28

12.Outlaw JJ, Wilborn CD, Smith-Ryan AE, Hayward SE, Urbina SL, Taylor LW, et al. Acute effects of a commerciallyavailable pre-workout supplement on markers of training: A double-blind study. J Int Soc Sports Nutr. 2014;11(1): 1-9. https://doi.org/10.1186/s12970-014-0040-0

13.Draper N, Whyte G. Anaerobic Performance Testing. 2012.

14.Gallardo-Fuentes, Francisco; Gallardo-Fuentes, Jorge; Ramírez-Campillo, Rodrigo; Balsalobre-Fernández, Carlos; Martínez, Cristian; Caniuqueo, Alexis; Cañas, Rodrigo; Banzer, Winfried; Loturco, Irineu; Nakamura, Fabio Y.; Izquierdo M. Intersession and Intrasession Reliabiliy and Validity of the My JumpApp for Measuring Different Jump Actions in Trained Male and Female Athletes. J Strength Cond Res. 2016;30(7): 2049-56. https://doi.org/10.1519/JSC.0000000000001304

15.Balsalobre-Fernández C, Glaister M, Lockey RA. The validity and reliability of an iPhone app for measuring vertical jump performance. J Sports Sci, 2015;33(15): 1574-9. https://doi.org/10.1080/02640414.2014.996184

16.Can İ, Han HCİ. Yoyo Aralıklı Toparlanma Testleri ve Sportif Performans Üzerine Genel Bir Değerlendirme [A general evaluation on athletic performance and yo-yo intermittent recovery tests]. Ankara Üniv Spor Bil Fak, 2013;11(2):8194.

17.Krustrup P, Mohr M, Amstrup T, Rysgaard T, Johansen J, Steensberg A, et al. The Yo-Yo intermittent recovery test: Physiological response, reliability, and validity. Med Sci Sports Exerc. 2003;35(4): 697-705. https://doi.org/10.1249/01.MSS.0000058441.94520.32

18.Nudler E, Gottesman ME. Transcription termination and anti-termination in Escherichia coli. Genes to cells. 2002; 7: 755-68. 
19.Kraemer WJ, Hatfield DL, Spiering BA, Vingren JL, Fragala MS, Ho JY, et al. Effects of a multi-nutrient supplement on exercise performance and hormonal responses to resistance exercise. Eur J Appl Physiol. 2007;101(5): 637-46. https://doi.org/10.1007/s00421-007-0535-3

20.Dawes JJ, Campbell B, Ocker LB, Temple DR, Carter JG, Brooks KA. The Effects of a Pre-Workout Energy Drink on Measures of Physical Performance. Int $J$ Phys Educ Fit Sport. 2014;3(4): 122-31. https://doi.org/10.26524/14420

21.Urbina S, Hayward S, Outlaw J, Holt J, Burks B, Cox B, et al.
Performance and body composition effects of a pre-workout supplement and post-workout protein intake in trained crossfit individuals. J Int Soc Sports Nutr, 2013;10(Suppl 1): 28. https://doi.org/10.1186/1550-2783-10-S1-P28

22.Smith A, Fukuda D, Kendall K, Graef J, Moon J, Stout J. The combined effects of a pre-workout supplement and three weeks of high-intensity interval training on critical velocity, anaerobic running capacity, training volume, and body composition in men and women. $J$ Int Soc Sports Nutr, 2009;6(Suppl 1):16. https://doi.org/10.1186/1550-2783-6-S1-P16

\section{Information about the authors:}

Çetin O. (Corresponding author); http://orcid.org/0000-0001-6841-5518; onatcetin2007@gmail.com; Faculty of Sport Sciences, Sakarya University of Applied Sciences; Esentepe Campus Serdivan Sakarya, 54050, Turkey.

Yaşar M.N.; http://orcid.org/0000-0003-1334-4630; merveyasar@sakarya.edu.tr; Faculty of Sport Sciences, Sakarya University of Applied Sciences; Esentepe Campus Serdivan Sakarya, 54050, Turkey.

Demirtaş B.; http://orcid.org/0000-0002-4720-7493; barbarosdemirtas54@gmail.com; Faculty of Sport Sciences, Sakarya University of Applied Sciences; Esentepe Campus Serdivan Sakarya, 54050, Turkey.

Beyleroğlu M.; http://orcid.org/0000-0002-2223-0064; mbeyler@sakarya.edu.tr; Faculty of Sport Sciences, Sakarya University of Applied Sciences; Esentepe Campus Serdivan Sakarya, 54050, Turkey.

Eker S.; http://orcid.org/0000-0001-5972-2428; salihekerdr@hotmail.com; Ministry of Health Sakarya University Education and Research Hospital; Adnan Menderes Ave. Sağlık St. No: 195 Adapazarı-Sakarya 54100. Turkey.

Gürkan A.C.; http://orcid.org/0000-0002-3977-0091; dralper06@mynet.com ; Iğdır University, Physical Education and Sports High School; lğdır, Turkey.

\section{Cite this article as:}

Çetin O, Yaşar MN, Demirtaş B, Beyleroğlu M, Eker S, Gürkan AC. Acute effects of pre-workout supplement on aerobic and anaerobic performance in basketball players. Physical education of students, 2019;23(1):16-22.

https://doi.org/10.15561/20755279.2019.0103

The electronic version of this article is the complete one and can be found online at: https://sportedu.org.ua/index.php/PES/issue/archive

This is an Open Access article distributed under the terms of the Creative Commons Attribution License, which permits unrestricted use, distribution, and reproduction in any medium, provided the original work is properly cited http://creativecommons.org/licenses/by/4.0/deed.en

Received: 18.12.2018

Accepted: 16.01.2019; Published: 28.02.2019 